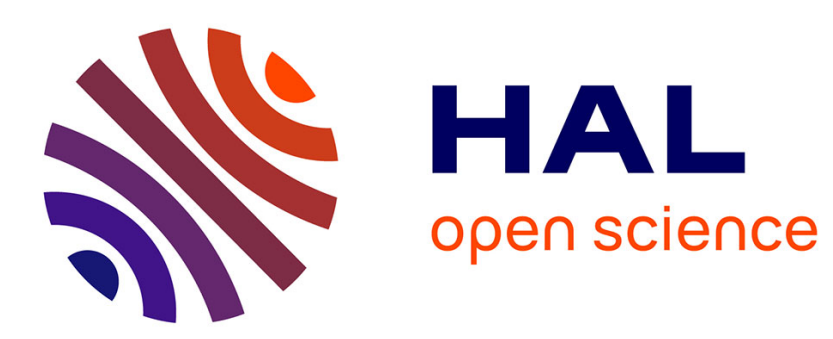

\title{
On the relevance of low-carbon stock indices to tackle climate change
}

Manuel Coeslier, Céline Louche, Jean-François Hétet

\section{To cite this version:}

Manuel Coeslier, Céline Louche, Jean-François Hétet. On the relevance of low-carbon stock indices to tackle climate change. Journal of Sustainable Finance \& Investment, 2016, 10.1080/20430795.2016.1223471. hal-01356163

\section{HAL Id: hal-01356163 https://hal.science/hal-01356163}

Submitted on 25 Aug 2016

HAL is a multi-disciplinary open access archive for the deposit and dissemination of scientific research documents, whether they are published or not. The documents may come from teaching and research institutions in France or abroad, or from public or private research centers.
L'archive ouverte pluridisciplinaire HAL, est destinée au dépôt et à la diffusion de documents scientifiques de niveau recherche, publiés ou non, émanant des établissements d'enseignement et de recherche français ou étrangers, des laboratoires publics ou privés. 


\title{
On the relevance of low-carbon stock indices to tackle climate change
}

\author{
Manuel Coeslier \\ Ecole Centrale Nantes, Mirova \\ manuel.coeslier@mirova.com \\ Céline Louche \\ Audencia Business School \\ Jean-François Hetet \\ Ecole Centrale Nantes
}

\section{Abstract}

In a context where the necessary transition to a climate-resilient economy creates financing needs as well as new and underestimated financial risks for investors, low-carbon or carbonefficient financial indices represent a rapidly growing and promising instrument. By building and testing representative optimization methodologies for low-carbon stock indices, this study investigates their ability to both (i) allow investors to hedge against climate-related financial risks and (ii) promote companies with higher contribution to the energy transition. The analysis is based on a large European stock index for which we benefit from a complete set of bottom-up calculated environmental indicators, including indirect and avoided carbon emissions figures. The results indicate that mainstream low-carbon indices methodologies fail to address the challenges they are based on and call for further improvements in order to align diversified financial instruments with ambitious climate objectives.

\section{Keywords}

Sustainable finance; lowcarbon indices; Carbon footprint; Financed emissions; Avoided emissions 


\section{Introduction}

The COP 21 in 2015 and its Paris agreement have made the fight against climate change become more material than ever. Even the $2^{\circ} \mathrm{C}$ threshold has been discussed and it is now acknowledged that "efforts [should be pursued] to limit the temperature increase to $1.5^{\circ} \mathrm{C}$ above pre-industrial levels" (UNFCCC 2015, Article 2 page 24). Achieving such goals will involve strong commitments from the financial system in order to secure investment flows towards adequate technologies in the fields of renewable energy and energy efficiency. The private sector has a crucial role to play in this transition and sees drivers for it become more and more compelling. In addition to stronger regulatory policies at regional levels, that incentivize investors to understand and report on their impact on climate, every investor now considers climate change as a risk that should be considered in strategic decisions. The question is only how much this risk should be yet internalized in financial analysis. Some socially responsible investors or universities endowment funds such as Stanford have already for long excluded coal mining or oil \& gas companies from their investment portfolios (Ritchie and Dowlatabadi 2015). The current momentum - progressively pushed by the legislation like in France ${ }^{1}$ - however leads big institutional investors to question whether and how they should actively manage the growing array of risks related to climate change and therefore changes the debate since there is evidently less leeway for them than for small investors (WRI and UNEP-FI 2015). Along with the growing debate on stranded assets, it is now clear that environmental externalities are not sufficiently and adequately being internalized in companies' financial valuations, leading to biased investment choices in a context of climate change. Traditional stock indices suffer from this situation, since they reflect the current listed economy in which fossil fuel related companies still play an important role. This verdict on the one hand and the need for largely diversified financial instruments by institutional investors on the other hand have led major index providers to offer what is known as "low-carbon" stock indices: indices that closely track market indices while reducing underlying carbon emissions in order to reduce the exposure to risks that could occur in a context of climate change.

As these indices progressively are gaining ground, this article investigates two questions (i) do low carbon stock indices allow investors to hedge against carbon risks, defined as all nonphysical climate change factors facing assets and companies, and (ii) what is their ability to reallocate capital flows towards solutions for the energy transition.

In order to understand the issues at stake, we first describe how to assess corporate performance regarding climate change, the different ways in which an investor can take credit for absolute carbon emission from its investees, and why these methods are imperfect. We then describe metrics that allow for a better understanding of the net impact of investments on the energy transition. Finally, we apply current methodologies used to build low-carbon indices to a representative European stock index in order to estimate their effectiveness in light of the different metrics we suggest.

\footnotetext{
${ }^{1}$ See article L533-22-1 from the "Code Monétaire et Financier modifié » modified by article 173 from the " loi sur la Transition Energétique »

http://www.legifrance.gouv.fr/affichCodeArticle.do;jsessionid=B1DA8573CC7711F3CD619B4A54A90386.tpdila 15v_1?idArticle=LEGIARTI000031063369\&cidTexte=LEGITEXT000006072026\&categorieLien=id\&dateTexte=201 61231
} 


\section{Carbon Impact of companies}

Although Greenhouse Gases (GHG) ${ }^{2}$ are not the only source of environmental impact (Finkbeiner 2009), limiting - and decreasing - their emissions is the most important challenge in the short term to tackle climate change and contain the rise in average temperatures to below $2^{\circ} \mathrm{C}$ (UNFCCC 2015). Thus, carbon emissions are one key indicator to assess the impact of a company on climate (Schaltegger et al. 2015). In a life-cycle approach, the impact of a company on climate is not only a function of its internal manufacturing processes but also of the raw materials it uses, the quantity and nature of the energy it consumes (inputs) and finally the products and services it sells to its customers (outputs). The measure of carbon emissions is often described as 'carbon footprint'. If applied to an entire company, this metric must be formally defined prior to use: "The Carbon Footprint is a measure of the exclusive total amount of carbon dioxide emissions that is directly and indirectly caused by an activity or is accumulated over the life stages of a product" (Wiedmann and Minx 2008, page 4). The key notion here is the perimeter considered: a company producing goods that pollute at the stage of their use (a car manufacturer, for example) should be considered with as much attention as a company producing goods that pollute at the manufacturing stage of their life (such as a cement producer).

The various scopes which can be differentiated in the analysis of carbon emissions have been defined in the early 2000s and regularly revised since then, mainly by the GHG Protocol (WBCSD and WRI 2010) and the French Environment and Energy Management Agency (ADEME 2014):

(i) Scope 1 emissions: All direct GHG emissions

(ii) Scope 2 emissions: Indirect GHG emissions from consumption of purchased electricity, heat or steam

(iii) Scope 3 emissions: Other indirect emissions, such as the extraction and production of purchased materials and fuels, transport-related activities in vehicles not owned or controlled by the reporting entity, electricity-related activities (e.g. Transmission and Distribution losses) not covered in Scope 2, outsourced activities, waste disposal, etc. The choices made by companies when they calculate and report their carbon emissions (Figure 1) are therefore crucial and should be consistent to ensure comparability of the results (both in time and across companies).

\footnotetext{
${ }^{2}$ Since every Greenhouse Gas can be expressed in terms of carbon equivalent $\left(\mathrm{CO}_{2} \mathrm{e}\right)$, they will be described using the generic term of 'carbon' throughout the article
} 


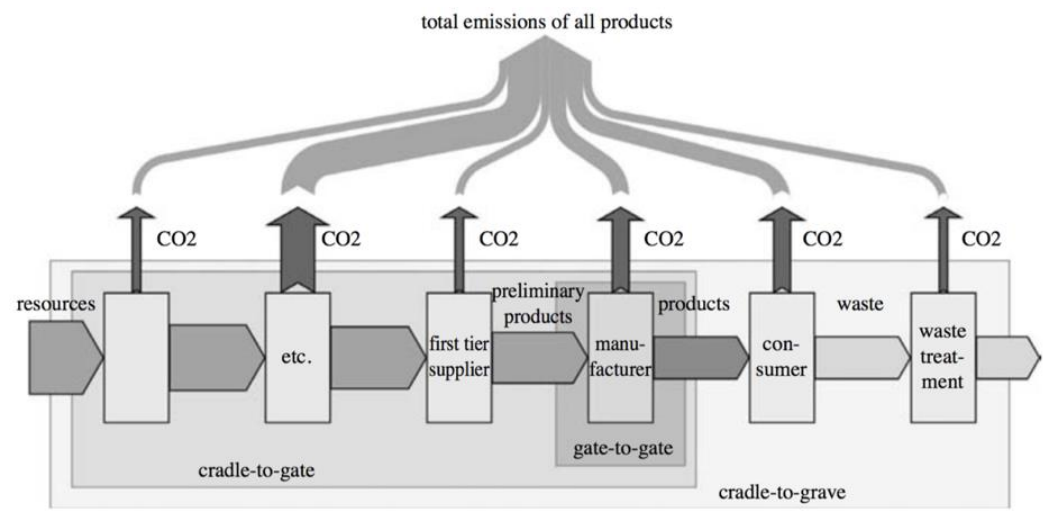

Figure 1 : Boundaries for GHG accounting at company level (Source: Schmidt 2009)

Today most companies report on their direct emissions (scope 1) and indirect emissions due to electricity consumption (scope 2) (Sullivan and Gouldson 2012). Indirect emissions due to resources used (inputs) and use/consumption of products sold (outputs) are either calculated within a very limited perimeter or not at all (Kolk, Levy, and Pinkse 2008). Information is accessible in annual reports or gathered by specialised data providers like CDP (Coeslier 2014).

In the end, there remain several limitations to the comparison of emissions from one company to another:

(i) If the perimeter is the same, it is not obvious that the methodology used to calculate emissions is the same. Two companies in the same sector could use different calculation methodologies (e.g. emissions factors) depending on the degree of accuracy of the methodology: worldwide emissions factors, region-specific emissions factors depending on the electricity mix etc.

(ii) If the perimeter is not the same, there is no reason to compare emissions.

(iii) Finally, absolute emissions are a function of a company's size and should therefore be translated into some form of intensity to compare the impacts of distinct companies or to track one company's impact over time. This is made possible through the use of other physical metrics in certain sectors: Two electricity producers can, for example, be compared through their respective $\mathrm{tCO}_{2} / \mathrm{kWh}$, allowing for a comparison of carbon emitted per unit of output produced. However, as soon as we want to compare companies with diversified activities across various sectors over time, there is no relevant one-fits-all physical metric and an economical factor should be used; revenue, market capitalization or enterprise value could all be used in order to create a relative indicator in $\mathrm{tCO}_{2} / €$ applicable to every company.

The precise way in which carbon emissions are calculated is subject to many assumptions and different indicators: gases considered, perimeter chosen, and the intensity as calculated with a physical or a financial factor (Hoffmann and Busch 2008; Pandey, Agrawal, and Pandey 2011). When looking at a given company, it is possible to interpret absolute carbon emissions in order to understand the contribution of each manufacturing step to overall totals. Dividing carbon emissions by revenue allows for analysis of their evolution over time without a size bias (such as if carbon emissions increase by $10 \%$ while revenue increases by $20 \%$ ). As previously mentioned, some indicators can be relevant to specific sectors like $\mathrm{CO}_{2} / \mathrm{t} . \mathrm{km}$ or 
$\mathrm{CO}_{2} / \mathrm{km}$.passenger for freight and passenger transport, respectively. (Hoffmann and Busch 2008)

In the end, carbon accounting at company level is subject to many assumptions and while harmonisation of methodologies is not necessarily needed to analyse a given company and inform strategic decision making at company level, harmonisation is needed once several companies are put together or compared to each other. This is typically the case of an investor, holding an investment portfolio composed of many companies in many different sectors and who wants to better understand his overall exposition to risks that could affect carbon-intensive assets in a context of climate change. The growing role of financial regulation in climate change mitigation has brought several question to investors: How much carbon emissions am I responsible for? What is my exposure to carbon risks? Does my investment contribute to a world on track with the $2^{\circ} \mathrm{C}$ threshold?

\section{From corporate emissions to financed emissions}

There are two main methodological approaches for estimating carbon emissions induced by a financing activity. The "bottom-up" approach consists in summing the emissions induced by each asset or project inside the investment portfolio. This approach is particularly suited for the observation of a limited universe, allowing for a detailed analysis. On the other hand, the "top-down" approach consists in attributing the total emissions of the overall economy to its financers (through bank debt, bond debt and equity) depending on their market share in each geographical and sectorial area (Gerardi, Grandjean, and Martinez 2015). This approach, based on publicly available emissions factors and banks' balance sheets data, is suited for a very large universe for which a detailed analysis would be prohibitively time-consuming and doesn't allow the comparison of specific actors.

Even if the choice is made to use a bottom-up approach, which is more precise by nature, measuring the carbon emissions induced by an investment ultimately implies using an allocation rule: how much of the emissions is an investor responsible for? Again, there are two ways to allocate emissions to an investor and each has strong implications (Thomae and Coeslier 2015), but they both employ a financial denominator.

We named the first way to allocate emissions "the shareholder method". In this approach shareholders of a company are considered to hold sole responsibility for its emissions, in which case market capitalization is used to multiply the amount invested by a factor in $\mathrm{tCO}_{2} / € \mathrm{mkt}$ cap. The alternative, which we named "the financer method", is to consider creditors and shareholders equally responsible for the emissions of a company since creditors also represent a source of financing for carbon-emitting tangible assets. In this case, the ratio used is $\mathrm{tCO}_{2} / €$ of enterprise value, with the assumption that cash and preferred stock are negligible compared to market capitalization and net debt. ${ }^{3}$ (Thomae and Coeslier 2015) Although we believe this is a reasonable first approximation, the methodology's precision will certainly evolve going forward. A good example comes from the financial sector, for which there is no calculation for enterprise value. Therefore, if one wants to integrate financial sector's carbon emissions in the analysis of its portfolio, a proxy for enterprise value has to be defined. Evidently, the choice of ratio has strong implications in the applicability of the methodology.

\footnotetext{
${ }^{3}$ The definition of Enterprise Value (EV) being the sum of future discounted cash flows (DCF) or EV = Market Capitalization + Total Debt - Cash
} 
For instance, only the use of the Enterprise Value enables the analysis of a portfolio with both equity and bonds.

Table 1: Examples of allocation rules to the investor

\begin{tabular}{|c|c|c|c|c|c|}
\hline \multirow{2}{*}{\multicolumn{2}{|c|}{ Fictive company }} & \multirow{3}{*}{$\begin{array}{c}\begin{array}{c}\text { Distribution of } \\
\text { enterprise value }\end{array} \\
50 \% \\
\end{array}$} & \multirow{2}{*}{$\begin{array}{c}\% \text { of } \\
\text { company's } \\
\text { assets held in } \\
\text { portfolio }\end{array}$} & \multicolumn{2}{|c|}{ Financed emissions in \% of total emissions of the company } \\
\hline & & & & $\begin{array}{c}\text { Shareholder method (using } \\
\text { market capitalisation) }\end{array}$ & $\begin{array}{l}\text { Financer method (using } \\
\text { enterprise value) }\end{array}$ \\
\hline \multirow{2}{*}{ Case 1} & Equity & & $100 \%$ & \multirow{2}{*}{$100 \%$} & \multirow{2}{*}{$50 \%$} \\
\hline & Debt & $50 \%$ & $0 \%$ & & \\
\hline \multirow{2}{*}{ Case 2} & Equity & $50 \%$ & $0 \%$ & \multirow{2}{*}{$0 \%$} & \multirow{2}{*}{$50 \%$} \\
\hline & Debt & $50 \%$ & $100 \%$ & & \\
\hline
\end{tabular}

Table 1 shows the major implications of the method chosen to allocate carbon emissions to an investment. In both cases, the contribution of the portfolio to the financing of the company is the same since the company issues shares and bonds equivalently. However, with the shareholder method, the emissions associated with the investment portfolio vary from $0 \%$ to $100 \%$ depending on the type of asset the portfolio is invested in. Using the financer method, the investment will always be associated to the same amount of carbon emissions, no matter the asset allocation chosen, between equity and bonds.

Mercer's study from 2011 has already analysed the role different asset classes have to - or will - play in the context of the energy transition and on their respective exposure to the risks related to climate change: which asset classes should be most impacted, by which factor (volatility, earnings) by region and by climate scenario (Mercer 2011). However, there is no global, detailed and quantified consensus as of yet and we will therefore treat both sources of financing (equity and debt) equally in order to link carbon emissions with investment flows. Thus, one euro invested in one company's bond will be allocated the same amount of carbon emissions as one euro invested in the same company's equity (Figure 2).



Figure 2 : Attribution of corporate carbon emissions to investor through the financer method 


\section{Assessing the contribution to the energy transition}

Calculating total carbon emissions induced by an investment portfolio provides a measure of impact, not performance. A measure of performance - or net impact - which would indicate the contribution of investments to achieving climate goals implies further indicators. The measure of carbon emissions induced alone cannot be a measure of performance because a company in the field of telecommunications could potentially have the same carbon emissions as a company producing wind turbines. The latter may display higher direct carbon emissions (scope 1) than the former since the manufacture of wind turbines is inherently a non-negligible source of carbon, yet the company producing wind turbines simultaneously provides an alternative means of electricity production much less carbon-intensive than traditional sources based on fossil fuels (coal- or gas-fired power plants). This reasoning can be extended to portfolios: a portfolio based only on companies involved in the energy transition will certainly show greater induced carbon emissions than a portfolio based only on companies from the tertiary sector.

This calls for new indicators which allow assessment of a portfolio's contribution to the energy transition. Measurement of carbon possesses a crucial strength due to its transversal nature: no matter the sector, carbon emissions can be measured over a wide perimeter of company action. In order to assess the performance of a company, a measure of "avoided" carbon emissions seems particularly relevant: this is the quantity of carbon that would have been emitted without the efforts put forth by a company to improve its manufacturing processes, the use of its inputs, or the efficiency of its outputs. The measurement of avoided emissions is already framed at company level in certain sectors, such as chemicals (ICCA and WBCSD 2013), or at project level, where it has been particularly used in green bond analysis (Arndt 2015). Wind turbine manufacturers are thereby attributed avoided emissions, as wind turbines produce electricity with greatly diminished induced emissions compared to traditional, fossil fuel-based electricity sources. Thus, to calculate and deduct avoided emissions, a sectorspecific reference must be set to compare with induced emissions.

Therefore, we use a measure of avoided emissions to assess not just a company's impact on the climate, but rather its performance. Even so, the association between induced and avoided carbon emissions is not enough to lead to a complete judgment on a company regarding climate change. Strategic choices like long-term commitments or capital and R\&D expenditures will not be directly translated into quantitative changes in carbon emissions, and the wide variety of performance indicators (Székely and Knirsch 2005) cannot easily be translated into one single indicator using a quantitative method. As a result, a qualitative assessment is still necessary to qualify the alignment of a company's global strategy with the needs of the energy transition.

To sum up, here are the key elements that needs to be considered in order to properly assess the performance of an investment portfolio regarding climate through the measure of carbon emissions:

- Not only direct emissions (scope 1) and indirect emissions from energy consumption (scope 2) need to measured, but also indirect emissions all along the supply chain (scope 3 upstream) and the use of sold products (scope 3 downstream) in order to catch all the risks related to negative climate performance. Indeed, a car or a plane manufacturer can have similar scope 1 and 2 emissions to a cosmetics producer and the risks faced by 
(thermal) car or plane manufacturers in a context of strong policies to reduce oil \& gas consumption can only be perceived through the measure of downstream scope 3 emissions.

- Total Induced emissions (scope 1,2 and 3) are only a measure of negative impact. A wind turbine producer will be allocated induced emissions due to the use and extraction of various materials, the construction and the end of life of the turbines. However, the fact that wind turbines allow for a much less carbon-intensive electricity production should be somehow rewarded. Therefore, avoided emissions are calculated as the emissions that would have normally been emitted without the efforts put forth by companies.

- Finally, the strategy and goals set by companies towards climate change are not directly made tangible by induced or avoided emissions. Therefore, a qualitative assessment of companies' engagement towards climate change mitigation needs to performed and cannot be replaced by quantitative figures.

Now that we have underlined the precautions one must take to assess the climate friendliness of an investment, we will analyse how investment portfolios and indices are built for institutional investors and what methods are currently being used to hedge these portfolios against climate change-related risks.

\section{Low-Carbon Indices}

\section{Origin of index investing}

Index-based investment strategies originate from Markowitz's Modern Portfolio Theory (Markowitz 1952), its application by Sharpe in the Capital Asset Pricing Model (Sharpe 1964) and further developments such as the 3 Factor Model (Fama and French 1992). The argument for passive index-based investment strategies are based on two major assumptions, namely that markets are efficient and return on investment follows a normal distribution (Burton $G$. Malkiel 2003). A passive index-based investment strategy is not only the result of Modern Portfolio Theory (market efficiency) but also market infrastructure (Della Croce, Stewart, and Yermo 2011) and its limits: short-termism (Mark Carney 2014) and herd behaviour (Sushil Bikhchandani and Sunil Sharma 2000). Such a strategy thus results in the reproduction of a market index representative of the listed economy. As the number of assets in the portfolio is smaller than that of the related index, the main objective is to maintain high diversification in order to minimize investment risk. There are several indicators to measure the "distance" between a portfolio and its benchmark (the parent market index) (Richard C. Grinold and Ronald N. Kahn, n.d.), that also describes the risks taken by the investor. One of the most common is the Tracking Error or active risk, a relative measure defined as the standard deviation of differences between returns of the portfolio and returns of the benchmark; an absolute measure would be the standard deviation of returns from the managed portfolio alone (Hoe et al. 2010).

\section{Climate Change in Investment Choices}

The number of financial indices built around the issues of climate change has been rapidly growing over the past ten years (Figure 3), but the means of integrating climate change parameters into index investing can be very different. Some indices exclude all companies involved in sectors considered to be the most polluting, while others favour sectors which provide solutions to the energy transition and are therefore focused on renewable energy 
and/or energy efficiency. However, these types of indices are based on important sectorial bets that limit diversification and involve greater misalignment with traditional market indices. Thus, these indices are not accessible to large institutional investment because of their risk profile: high tracking-error compared to benchmark indexes.

In the meantime, over the past few years there has been a growing consensus that risks related to climate change are not being internalized in companies' valuations and that stock markets are therefore exposed to a risk not sufficiently and adequately quantified (Stern 2007). Civil society also plays an important role through divestment campaigns against fossil fuels (coal, oil \& gas) (Caldecott, Ansar, and Tilbury 2013), first impacting universities' endowment funds such as Stanford's (Ritchie and Dowlatabadi 2015) and now also reaching institutional investors who gather into various initiatives like the Portfolio Decarbonization Coalition ${ }^{4}$ or the Montreal Pledge 5 .

This momentum has led traditional index providers to offer means for integrating climate change issues into broadly diversified investment strategies, therefore very different from more actively managed inclusive and exclusive indices. Their aim is to offer a product very similar to reference stock market indices (Climate Change Support Team of the UN Secretary General 2015) - which results in low tracking error - while hedging against risks that are not sufficiently - or not at all - internalized today at the same time, especially risks related to climate change (Anderson, Bolton, and Samama 2014). This second characteristic typically translates into a lower direct "carbon intensity" of the portfolio as compared to its reference index (benchmark). The first provider of such an investment instrument has been Euronext in 2008, quickly followed by other traditional index providers like S\&P, MSCI or FTSE but also by newly specialized index providers like Solactive or ETIndex.



Figure 3: Cumulative number of low-carbon/climate change related indices (Source: Climate Change Support Team of the UN Secretary General 2015, from Vivid Economics and based on BNEF data)

\footnotetext{
${ }^{4}$ http://unepfi.org/pdc/

${ }^{5}$ http://montrealpledge.org/
} 
Figure 3 shows how much the apparition of diversified low-carbon indices has closely followed the global momentum of climate change related indices that are not necessarily designed for passive index based investment.

\section{Methodology}

As of April 2016, large-scale (Europe, World) low-carbon indices differentiate themselves through their objectives and the construction methodologies upon which they are based. These indices allow for a diversified investment through a large number of stocks (Table 2).

Table 2: Global diversified low-carbon stock indices

\begin{tabular}{|c|c|c|c|c|}
\hline Provider & Index or Index Family & $\begin{array}{l}\text { Parent Index or } \\
\text { Benchmark }\end{array}$ & Coverage & $\begin{array}{l}\text { Number of } \\
\text { constituents }\end{array}$ \\
\hline $\mathrm{MSCl}$ & $\begin{array}{l}\text { ACWI Low Carbon } \\
\text { Target Index }\end{array}$ & $\mathrm{MSCl} A C W I$ & World & 1730 \\
\hline $\mathrm{MSCl}$ & $\begin{array}{l}\text { ACWI Low Carbon } \\
\text { Leaders Index }\end{array}$ & MSCI ACWI & World & 1951 \\
\hline S\&P/IFCI & Carbon Efficient Index ${ }^{8}$ & S\&P Global 1200 & World & 1200 \\
\hline STOXX & Low Carbon Indices ${ }^{9}$ & STOXX Global 1800 & World & 1800 \\
\hline
\end{tabular}

The following table shows what indicators can be used in methodologies to develop global diversified low-carbon indices. Some can be used both as objectives (minimized or maximized variables) and constraints (capped variables) depending on the optimization process while other can only be used as constraints.

Table 2: Optimization parameters used to build low carbon indices

\begin{tabular}{|l|l|c|c|}
\hline Variable & Definition & $\begin{array}{l}\text { Can be used as } \\
\text { Objective (maximised } \\
\text { or minimised) }\end{array}$ & $\begin{array}{l}\text { Can be used } \\
\text { as constraint } \\
\text { (capped) }\end{array}$ \\
\hline Tracking Error & $\begin{array}{l}\text { Standard deviation of active } \\
\text { returns }\end{array}$ & Yes & Yes \\
\hline $\begin{array}{l}\text { Scope 1 and 2 } \\
\text { carbon emissions }\end{array}$ & See above & Yes & Yes \\
\hline Sector neutrality & $\begin{array}{l}\text { No differences in sector } \\
\text { weights between portfolio } \\
\text { and benchmark }\end{array}$ & No & Yes \\
\hline Country neutrality & $\begin{array}{l}\text { No differences in country } \\
\text { weights between portfolio } \\
\text { and benchmark }\end{array}$ & \multicolumn{1}{|c|}{ No } & \\
\hline
\end{tabular}

\footnotetext{
${ }^{6}$ Methodology available at https://www.msci.com/eqb/methodology/meth_docs/MSCl_Low_Carbon_Target_Indexes_Methodology.pdf Accessed in April 2016

${ }^{7}$ Methodology available at https://www.msci.com/eqb/methodology/meth docs/MSCI Low Carbon Leaders Indexes Methodology.pdf Accessed in April 2016

8 Methodology available at

http://us.spindices.com/indices/equity/sp-ifci-carbon-efficient-us-dollar

Accessed in April 2016

${ }^{9}$ Methdology available at

https://www.stoxx.com/document/Indices/Common/Indexguide/stoxx_index_guide.pdf

Accessed in April 2016
} 


\begin{tabular}{|lc|l|c|c|}
\hline $\begin{array}{l}\text { Fossil } \\
\text { reserves }\end{array}$ & Fuel & $\begin{array}{l}\text { Proven }(\mathrm{P} 1) \text { fossil fuel } \\
\text { reserves in MBOe }\end{array}$ & Yes & Yes \\
\hline
\end{tabular}

On the basis of reference stock indices, "low-carbon" or "carbon-efficient" indices are the result of quadratic optimisations (with linear constraints) that use some of the indicators - or every of them - listed in table 2 . There is an infinity of combinations of these indicators to create a "low-carbon" index based on a given benchmark. Therefore, we propose three representative optimisations that consist in different combinations of the same indicators (Table 3).

Table 3: Set of representative optimization methods used to build low-carbon indices

\begin{tabular}{|c|c|c|c|}
\hline & Optimisation 1 & Optimisation 2 & Optimisation 3 \\
\hline Objective(s) & $\begin{array}{c}\text { Minimize Tracking- } \\
\text { Error }\end{array}$ & $\begin{array}{l}\text { Minimize scopes } 1 \& 2 \\
\text { carbon intensity }\end{array}$ & $\begin{array}{l}\text { Underweight } 20 \% \text { of the } \\
\text { most carbon-intensive } \\
\text { stocks by } 30 \% \text { and } \\
\text { overweight } 20 \% \text { of the least } \\
\text { carbon-intensive stocks by } \\
30 \% \text { (scope } 1 \& 2 \\
\text { emissions) }\end{array}$ \\
\hline Constraint(s) & $\begin{array}{l}\text { Maximum scope } 1 \& 2 \\
\text { carbon intensity and } \\
\text { fossil fuel reserves of } \\
50 \% \text { those of the } \\
\text { parent index } \\
\text { Maximum country } \\
\text { deviation of }+-2 \% \\
\text { Maximum sector } \\
\text { deviation of }+-2 \%\end{array}$ & $\begin{array}{l}\text { Maximum Tracking Error of } \\
30 \text { basis points } \\
\text { Maximum country deviation } \\
\text { of }+-2 \% \\
\text { Maximum sector deviation } \\
\text { of }+-2 \% \\
\text { Maximum fossil fuel } \\
\text { reserves of } 50 \% \text { that of the } \\
\text { parent index }\end{array}$ & No sector deviation \\
\hline
\end{tabular}

We use APTPro to run the different optimisations. We use proven reserves of Oil \& Gas at the end of the year in millions of Barrels of Oil Equivalent (BOE) provided by Bloomberg under the mnemonic "BOE_END_YEAR_WORLD". Enterprise values and benchmark weights are also accessed through Bloomberg. The country deviation refers to the country of domicile of companies in the benchmark. Therefore, if $20 \%$ of the benchmark is domiciled in the UK, a maximum $2 \%$ country deviation allows the optimised portfolio to have $18 \%$ to $22 \%$ of its value domiciled in the UK. The sector deviation refers to the GICS level 2 sectors. ${ }^{10}$

Regarding carbon emissions, we use data provided by Carbone 4, a French consultancy specialised in corporate carbon accounting that has developed a methodology called Carbon Impact Analytics (Carbone 4 2015) in order to provide investors and asset managers with the following figures:

- Total induced emissions by scope (scope 1,2 and 3)

- Total avoided emissions by scope (scope 1, 2, 3)

- A global assessment of a company's contribution to the energy transition (denoted CIA Global) which goes from 1 (strong contribution to the energy transition) to 5 (negative contribution to the energy transition) and integrates assessments of the company's strategy and investments made regarding climate change.

\footnotetext{
${ }^{10}$ https://us.spindices.com/documents/index-policies/gics-map-english-20150531.xlsx?force download=true
} 
To ensure comparability of the results, optimisation methods have been tested on the same universe composed with the Stoxx $600^{11}$, one of the major stock indices representing the European listed economy, as of February 2016. It will be considered the benchmark for optimised portfolios. Generally, portfolio P composed with $\mathrm{N}$ assets has a direct carbon intensity of:

$$
G H G_{-} \text {Intensity }_{1,2}(P)=\sum_{i=1}^{N} G H G_{-} \text {Intensity }_{1,2}(i) \cdot w_{i}
$$

Where

$$
G H G_{\text {Intensity }_{1,2}}(i)=\frac{G H G_{1,2}(i)}{\text { Enterprise Value }(i)}
$$

is the direct carbon intensity of asset $\mathrm{i}$ in $\mathrm{tCO}_{2} \mathrm{eq} / \mathrm{year} / \mathrm{M} €$ for which only scope 1 and 2 emissions are accounted for and $w_{i}$ is the weight of asset $i$ in the portfolio. Similarly,

$$
G H G_{-} \text {Intensity }_{\text {tot }}(P)=\sum_{i=1}^{N} G H G_{-} \text {Intensity }_{\text {tot }}(i) \cdot w_{i}
$$

represents total carbon intensity of the portfolio, for which scope 1, 2 and 3 are accounted for. As previously mentioned, Tracking-Error (T-E) is defined as standard deviation of relative returns (difference between returns of the portfolio and returns of the benchmark). There are two types of Tracking-Errors, ex-ante and ex-post, with different meanings and mathematical constructions. Ex-post Tracking-Error is calculated with variable (past) weightings of the stocks while ex-ante Tracking-Error is based on fixed weightings and represents a forecast. A $2 \%$ exante Tracking-Error for example indicates that there are two chances out of three that a portfolio's return will equal that of its benchmark in the following year, within $2 \%$. Sector neutrality ensures that one particular sector is not promoted to the detriment of another during the optimisation process.

\footnotetext{
${ }^{11}$ For further information see: https://www.stoxx.com/index-details?symbol=SXXP
} 


\section{Results and discussion}

Our first objective is to ensure the reproducibility of "low-carbon » indices methodologies regarding the indicators that are communicated by index providers, namely Scopes $1 \& 2$ carbon intensity, change in fossil fuel reserves intensity and Tracking-Error relative to the benchmark index.

Figure 4: Results of optimisations on indicators communicated by index providers

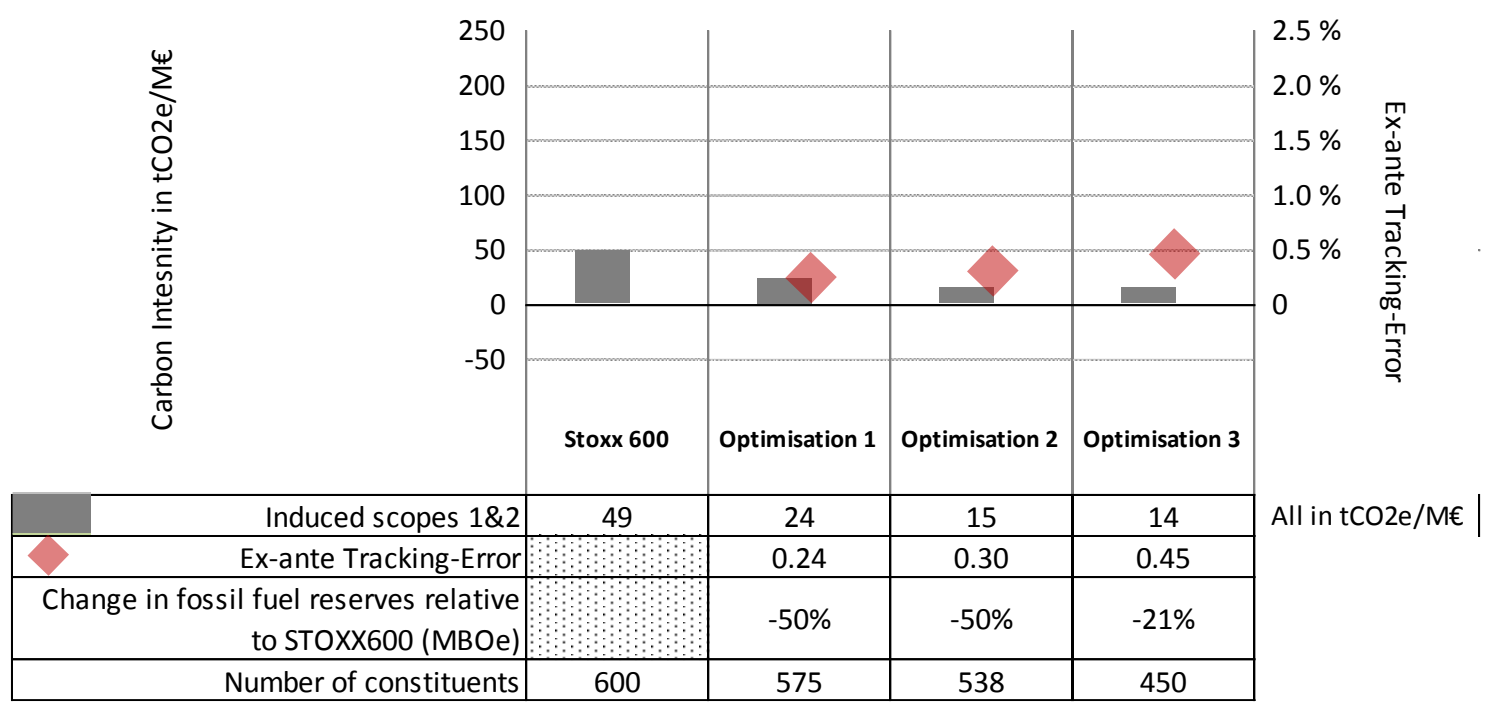

The indicators represented on figure 4 show that the three optimisations we have built to reproduce current "low-carbon" indexes methodologies are applicable. Indeed, no constraint is saturated by the end of each optimisation. In other words, it is perfectly possible to reduce the scopes $1 \& 2$ carbon intensity as well the fossil fuels reserves intensity by $50 \%$ while keeping an ex-ante Tracking-Error of less than $0.3 \%$ relative to the benchmark, the STOXX 600 .

As previously explained, the interest of managing only scopes $1 \& 2$ carbon intensity and fossil fuels reserves intensity may be very limited in order to reduce the exposure to risks related to climate change. Therefore, the ability of "low-carbon" indices to change the global carbon profile, including scope 3 indirect emissions and avoided emissions is key.

Figure 5 shows the exact same results as figure 4 but this time with indirect scope 3 emissions as well as avoided emissions and the weighted - previously mentioned - CIA global grade, reflecting the ability of the portfolio to contribute to climate change mitigation. 
Figure 5: Results of optimisations on every carbon related metrics

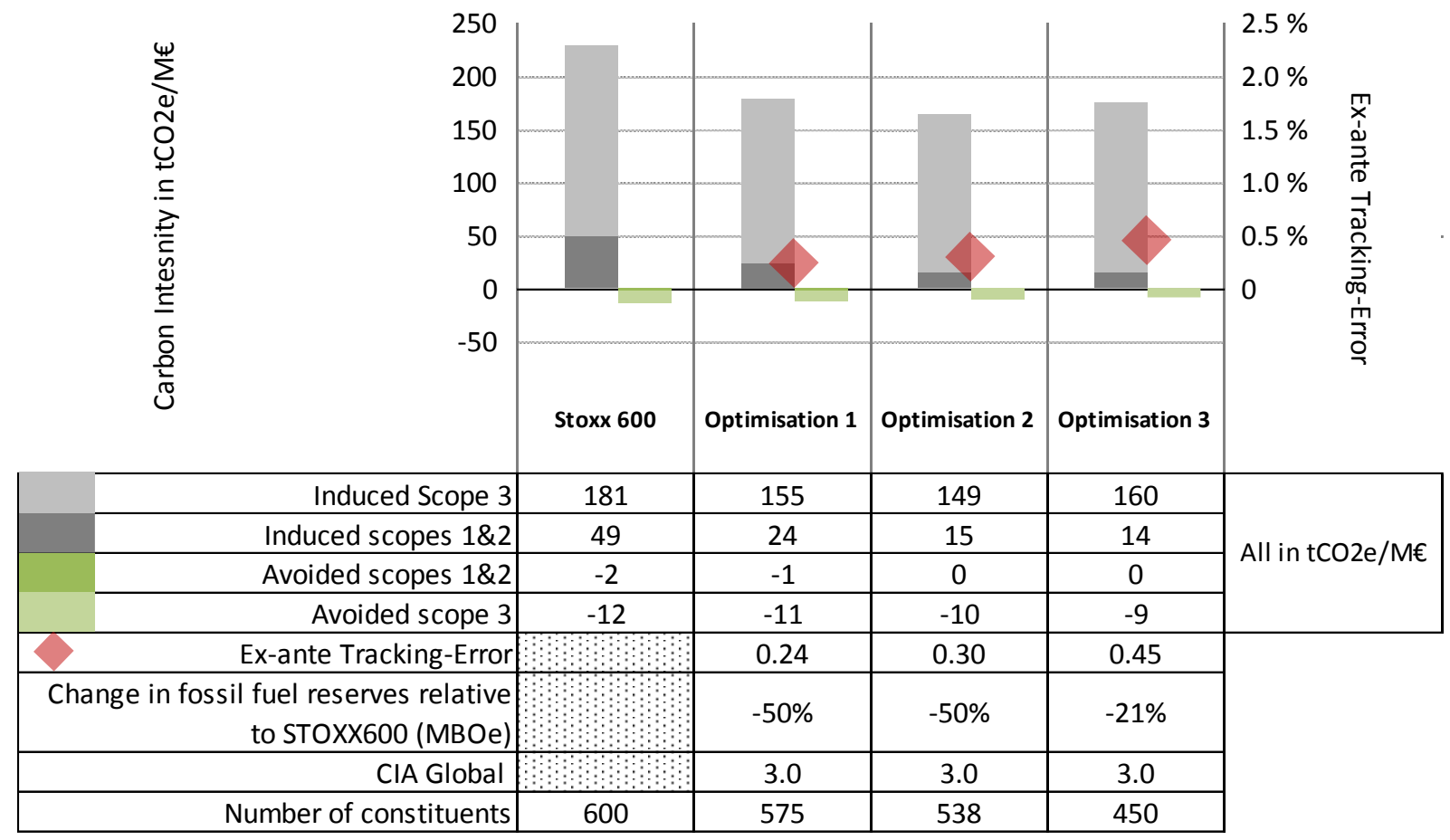

The benchmark, which is the starting universe of the optimizations, shows that indirect (scope 3 ) induced carbon emissions represent $79 \%$ of total emissions even if double counting of emissions is eliminated by Carbon Impact Analytics. Avoided emissions represent 14 $\mathrm{tCO}_{2} /$ year/M€, 16 times less than induced emissions. Fossil fuel reserves intensity is equal to $552 \mathrm{MBOe} / \mathrm{M}^{12}$ and it is created by only 10 companies among the 600 in the benchmark, all of them being classified in the oil \& gas or mining sectors.

The first optimization is constrained by environmental indicators: scopes 1 \& 2 carbon intensity and fossil fuels reserves intensity are capped at $50 \%$ those of the benchmark. The objectives are met with a Tracking-Error of 24 basis points $(0.24)$ that demonstrates a close distance to the benchmark. However, based on a complete set of environmental indicators, the effectiveness of the optimization process is limited with a decrease in total induced emissions of only $22 \%$ as well as a decrease in avoided emissions of $15 \%$. Moreover, the global score does not show any improvement in the contribution to the energy transition.

The second optimization program is constrained by a maximum tracking error of 30 basis points (0.3) and the objective is to minimize the direct carbon intensity while dividing fossil fuel reserves intensity by two. By saturating the tracking-error constraint, it is possible to achieve a $69 \%$ decrease in direct carbon intensity and a 50\% decrease in overall fossil fuel reserves intensity. However, the efficiency of this optimization process seems limited when looking at other indicators since total carbon intensity only decreases by $29 \%$ and avoided emissions intensity also decreases by $25 \%$. Furthermore, the global score does not show any progress due to the optimization process, meaning that the optimized portfolio does not contribute more to the energy transition than the benchmark.

\footnotetext{
12 Millions of barrels of oil equivalent
} 
Finally, the third optimization method leads to a $71 \%$ decrease in direct carbon intensity with a very limited impact on fossil fuel reserves intensity: a decrease of $21 \%$. Total portfolio induced carbon intensity decreases by $24 \%$ while avoided carbon intensity also decreases by $32 \%$. As for the first two optimisations, the global score remains steady, showing no improvement in the portfolio's contribution to climate change mitigation.

The results of these optimisations provide many lessons for any investor who wants to hedge against risks related to climate change by lowering their carbon intensity or even better contribute to the energy transition:

(i) Direct carbon emissions are not a proxy for total carbon emissions. Minimizing only direct carbon emissions therefore doesn't lead to the best possible carbon intensity and there is no reason to think that industries with only high indirect scope 3 carbon emissions will be less impacted by climate change than industries with only high direct scope 1 and indirect scope 2 carbon emissions.

(ii) Fossil fuel reserves are not a good enough proxy for indirect scope 3 carbon emissions. In fact, it is only a proxy in the extractive industry - oil and gas, mining - where the reserves rely but it is not applicable to every other industry with high indirect carbon intensity: transportation, building etc. It is therefore possible to have both a 50\% decrease in fossil fuel reserves intensity and scopes 1 \& 2 carbon intensity while having only a $22 \%$ decrease in overall carbon intensity.

(iii) Divesting from carbon intensive industries doesn't automatically result in investing into efficient companies. In other words, the simple focus on the decrease in induced scopes 1 \& 2 carbon emissions leads to some sort of climate "neutrality": the investment doesn't contribute to the energy transition more than before.

The results we show in this paper not only demonstrate the need for a better and more reliable carbon reporting at corporate level. By challenging the effectiveness of current "low-carbon" indices methodologies, we help investors address very different needs. First, investors who "only" want to manage their risk exposure, in particular the risks related to climate change, should easily understand the limits - and risks - of using only partial data to do so. Even if lowcarbon indices have paved the way for institutional investments with lower climate impact and therefore lower risk, we show that carbon risks need global carbon data to be managed adequately. Second, investors with the objective of a better contribution to climate change mitigation cannot rely on low-carbon indices to do so. The ability to finance solutions to the energy transition relies in indirect scope 3 and avoided carbon emissions as well as other forward looking indicators like investments and strategy of underlying companies. These observations call for new tools to the intention of institutional investors in order to (i) better manage the risks they face in a context of climate change and (ii) better contribute to the necessary financing of the energy transition. 


\section{Conclusion}

We show that it is possible to optimize a stock index in order to create a portfolio with very low Tracking-Error while simultaneously significantly minimizing its direct carbon emissions intensity, as Anderson, Bolton and Samama had already demonstrated (Anderson, Bolton, and Samama 2014). However, in light of more complete quantitative information about indirect and avoided emissions of companies coupled with qualitative information about their climate change-related performance, our analysis allows us to draw two important conclusions that mitigate the first result.

First, if the aim of "low-carbon" indices is to minimize carbon risks in the investment, hypothesis that these risks are positively correlated with direct carbon intensity, their present ability to do so becomes highly limited the moment global carbon intensity is considered. It also appears that minimizing fossil fuel reserves is not adequately effective to tackle this issue. Secondly, in light of every other indicator analysed, current optimization methods do not improve the contribution of portfolios to the financing of the energy transition; the quantity of avoided emissions does not rise and the investment exposure to solutions for the energy transition (renewable energy, energy efficiency) remains steady or decreases. More alarming yet is the potential for such methodologies to handicap - by lowering their access to capital - actors whose impact on the climate is clearly positive but located in their extended boundaries (an insulation provider for example), while benefitting actors whose direct impact is negligible but have highly polluting inputs or outputs (an aircraft manufacturer for example).

To answer our initial two questions, (i) "low-carbon" indices only partially allow investors to hedge against carbon risks and - at least - miss a wide range of potential risks located in industries with stakes located in their indirect perimeter of action and (ii) as long as the focus will only be on scopes $1 \& 2$ emissions or fossil fuel reserves, they are not tools to help finance the energy transition but rather tools to help run away from it.

In the end, traditional "low-carbon" indices cannot provide a satisfactory answer to investors who want to hedge against carbon risks or assess their contribution to the energy transition, already mandatory in France. The lack of data availability from corporates and quality around this topic represents the biggest constraints for making these methodologies more applicable to larger universes. However, in the absence of exhaustive quantitative data, and even in the context of a passive investment strategy, it remains possible to better account for climate change issues. To do so, it is necessary to question current investment strategies based on very low tracking error compared to market indices; based on an economy which doesn't seem to be compatible with a $2^{\circ} \mathrm{C}$ (or lower) scenario, the ambitious investments for the energy transition are not likely to match current benchmarks. Overall, active climate oriented investment strategies do not necessarily come at the expense of risk/return profile. In fact, integrating long-term risks and opportunities and financing the preservation of common goods is very likely to also create short-term benefits. 


\section{Acknowledgement}

We thank Carbone 4 (Alain Grandjean and Jean-Marc Jancovici) for the data they have given us access to and the discussions we had together on the methodology. We also gratefully acknowledge the comments and reviews of Hervé Guez and Ladislas Smia (Mirova) on early drafts and Mirova for the financial support and material provided.

\section{References}

ADEME. 2014. "Documentation des facteurs d'émissions de la Base Carbone." http://www.bilans-ges.ademe.fr/static/documents/\%5bBase\%20Carbone\%5d\%20Documenta tion\%20g\%C3\%A9n\%C3\%A9rale\%20v11.0.pdf.

Anderson, Mats, Patrick Bolton, and Frédéric Samama. 2014. "Hedging Climate Risk." https://www0.gsb.columbia.edu/faculty/pbolton/papers/Hedgingclimaterisk(v35).pdf.

Arndt, Matthew. 2015. "Impact Reporting." presented at the Green Bond Principles Conference, March 27.

http://www.icmagroup.org/assets/documents/Regulatory/Green-Bonds/EIB-Impact-Reporting -GBP_final-version-27-March-2015.pdf.

Burton G. Malkiel. 2003. "The Efficient Market Hypothesis and Its Critics." Journal of Economic Perspectives 17 (1): 59-82. doi:10.1257/089533003321164958.

Caldecott, Ben, Atif Ansar, and James Tilbury. 2013. "Stranded Assets and the Fossil Fuel Divestment Campaign: What Does Divestment Mean for the Valuation of Fossil Fuel Assets." Stranded Assets Programme, SSEE, University of Oxford.

http://www.fossilfuelsreview.ed.ac.uk/resources/Evidence\%20-\%20Investment,\%20Financial, \%20Behavioural/Smith\%20School\%20-\%20Stranded\%20Assets.pdf.

Carbone 4. 2015. "Carbon Impact Analytics."

http://www.carbone4.com/sites/default/files/CarbonImpactAnalytics.pdf.

Climate Change Support Team of the UN Secretary General. 2015. "Trends in Private Sector Climate Finance."

http://www.un.org/climatechange/wp-content/uploads/2015/10/SG-TRENDS-

PRIVATE-SECTOR-CLIMATE-FINANCE-AW-HI-RES-WEB1.pdf.

Coeslier, Manuel. 2014. "How to Improve Corporate Carbon/Climate Reporting to Better Inform Investment Decisions?" Master Thesis, Mines ParisTech. unpublished.

Della Croce, Raffaele, Fiona Stewart, and Juan Yermo. 2011. "Promoting Longer-Term Investment by Institutional Investors." OECD Journal: Financial Market Trends 2011 (1): 145-64.

Fama, Eugene F., and Kenneth R. French. 1992. "The Cross-Section of Expected Stock Returns." The Journal of Finance 47 (2): 427-65.

Finkbeiner, Matthias. 2009. "Carbon Footprinting-opportunities and Threats." The International Journal of Life Cycle Assessment 14 (2): 91-94. doi:10.1007/s11367-009-0064$\mathrm{x}$. 
Gerardi, Anne, Alain Grandjean, and Emmanuel Martinez. 2015. "La Quantification Des émissions de Gaz à Effet de Serre Des Institutions Financières." Revue D'économie Financière, no. 1: 189-204. doi:10.3917/ecofi.117.0189.

Hoe, Lam Weng, Jaaman Saiful Hafizah, Isa Zaidi, and others. 2010. "An Empirical Comparison of Different Risk Measures in Portfolio Optimization." Business and Economic Horizons 1 (1): 39-45.

Hoffmann, Volker H., and Timo Busch. 2008. "Corporate Carbon Performance Indicators." Journal of Industrial Ecology 12 (4): 505-20. doi:10.1111/j.1530-9290.2008.00066.x.

ICCA, and WBCSD. 2013. "Addressing the Avoided Emissions Challenges." http://www.icca-chem.org/iccadocs/E\%20CC\%20LG\%20guidance_FINAL_07-10-2013.pdf.

Kolk, Ans, David Levy, and Jonatan Pinkse. 2008. "Corporate Responses in an Emerging Climate Regime: The Institutionalization and Commensuration of Carbon Disclosure." European Accounting Review 17 (4): 719-45. doi:10.1080/09638180802489121.

Mark Carney. 2014. "The Future of Financial Reform." http://www.bankofengland.co.uk/publications/Documents/speeches/2014/speech775.pdf.

Markowitz, Harry. 1952. "Portfolio Selection." The Journal of Finance 7 (1): 77-91.

Mercer. 2011. "Climate Change Scenarios - Implications for Strategic Asset Allocation." http://www.ifc.org/wps/wcm/connect/6b85a6804885569fba64fa6a6515bb18/ClimateChangeS urvey_Report.pdf?MOD=AJPERES.

Pandey, Divya, Madhoolika Agrawal, and Jai Shanker Pandey. 2011. "Carbon Footprint: Current Methods of Estimation." Environmental Monitoring and Assessment 178 (1-4): 13560. doi:10.1007/s10661-010-1678-y.

Richard C. Grinold, and Ronald N. Kahn. n.d. "Active Portfolio Management."

Ritchie, Justin, and Hadi Dowlatabadi. 2015. Fossil Fuel Divestment: Reviewing Arguments, Implications \& Policy Opportunities. Vol. 28. Edited by Tom Pedersen. PICS White Paper Series. January.

http://climatechange.Ita.org/wp-content/uploads/cct/2015/03/Divestment-WP-Jan-2015FINAL.pdf.

Schaltegger, Stefan, Dimitar Zvezdov, Igor Alvarez Etxeberria, Maria Csutora, and Edeltraud Günther, eds. 2015. Corporate Carbon and Climate Accounting. Cham: Springer International Publishing. http://link.springer.com/10.1007/978-3-319-27718-9.

Schmidt, Mario. 2009. "Carbon Accounting and Carbon Footprint - More than Just Diced Results?" International Journal of Climate Change Strategies and Management 1 (1): 19-30. doi:10.1108/17568690910934372.

Sharpe, William F. 1964. "Capital Asset Prices: A Theory of Equilibrium under Conditions of Risk." The Journal of Finance 19 (3): 425-42. doi:10.2307/2977928.

Stern, Nicholas. 2007. "Identifying the Costs of Mitigation." In Stern Review: The Economics of Climate Change, 238-66. http://dx.doi.org/10.1017/CBO9780511817434.017. 
Sullivan, Rory, and Andy Gouldson. 2012. "Does Voluntary Carbon Reporting Meet Investors' Needs?” Journal of Cleaner Production 36 (November): 60-67. doi:10.1016/j.jclepro.2012.02.020.

Sushil Bikhchandani, and Sunil Sharma. 2000. "Herd Behavior in Financial Markets: A Review," IMF Working Paper, , no. 00/48 (March): 33.

doi:http://dx.doi.org/10.2139/ssrn.228343.

Székely, Francisco, and Marianna Knirsch. 2005. "Responsible Leadership and Corporate Social Responsibility:" European Management Journal 23 (6): 628-47. doi:10.1016/j.emj.2005.10.009.

Thomae, Jakob, and Manuel Coeslier. 2015. "Allouer Les Impacts Climatiques Aux Institutions Financières.” In Empreinte Carbone: évaluer et Agir. Développement Durable. Presses des MINES. http://www.pressesdesmines.com/developpement-durable/empreinte-carbone-evaluer-et-agir .html.

UNFCCC. 2015. "Adoption de l'Accord de Paris."

http://unfccc.int/resource/docs/2015/cop21/fre/l09f.pdf.

WBCSD, and WRI. 2010. "A Corporate Accounting and Reporting Standard." http://www.ghgprotocol.org/files/ghgp/public/ghg-protocol-revised.pdf.

Wiedmann, Thomas, and Jan Minx. 2008. "A Definition of 'carbon Footprint."' In Ecological Economics Research Trends, 1:1-11. Carolyn C. Pertsova. https://www.novapublishers.com/catalog/product_info.php?products_id=5999.

WRI, and UNEP-FI. 2015. "Carbon Asset Risk: Discussion Framework." http://www.unepfi.org/fileadmin/documents/carbon_asset_risk.pdf. 